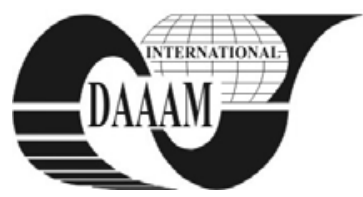

Annals of DAAAM for 2011 \& Proceedings of the 22nd International DAAAM Symposium, Volume 22, No. 1, ISSN 1726-9679 ISBN 978-3-901509-83-4, Editor B. Katalinic, Published by DAAAM International, Vienna, Austria, EU, 2011 Make Harmony between Technology and Nature, and Your Mind will Fly Free as a Bird Annals \& Proceedings of DAAAM International 2011

\title{
HOW CAN V-I CHARACTERISTICS HELP IN COUNTERFEIT COMPONENT DETECTION
}

\author{
NEUMANN, P[etr]; ADAMEK, M[ilan] \& SKOCIK, P[etr]
}

\begin{abstract}
The counterfeit electronic components represent a serious problem nowadays. This paper illustrates a V-I characteristic based counterfeit detector application possibilities. The electronic component V-I characteristics express a relationship between the current flowing via a chosen couple of pins, and the voltage applied on those pins. The applied voltage course follows a certain function like sinus, triangle or ramp between safe limits. The V-I characteristics of an individual component type can differ according to production technology, according to particular manufacturer, or according to the measurement conditions itself. The natural differences can be subsumed in the model component pin print which can be used for the comparative analysis aimed at discovering unnatural differences caused by improper treatment, failure or by the counterfeiting process.

Key words: counterfeit component, counterfeit detector, V-I characteristic, scan profile, pin print
\end{abstract}

\section{PROBLEM OF COUNTERFEIT COMPONENTS}

We can encounter counterfeited products at various complexity levels and in various product commodities. We are unfortunately encountering also counterfeited electronic components in a dramatically increasing rate in course of recent years. The counterfeit components types range over the passive and active components from stable precise resistors up to complex integrated circuits.

There exists a wide variety of electronic component counterfeits on the market. One extreme represents a chip-less package with relevant pin count and package labelling. On the other hand, we can encounter very elaborate counterfeit integrated circuit parametrically almost identical with original component, but for instance, with reduced reliability, narrower application temperature range, latent damages, or with other dissimilarities hardly detectable in production assembly process. Such components should undergo long time testing in a statistical set and in conditions supporting the manifestation of pertinent dissimilarities. A substantial part of counterfeit components is represented by refurbished components originating from electronic scraps. Their packages and leads are finished, and the components are labelled according to the customer's interest (Hammond, 2010). The counterfeit components penetration in supply chains threatens not only consumer electronic products quality and reliability, but also all sensitive systems in medical electronics, automation and control systems, weapon systems, civil and military aviation systems, space research systems etc. (Crawford et al., 2010).

The counterfeit component infiltration in product assemblies are influenced and promoted by several factors. Accessibility and price are playing a very important role. Cost reduction pressure may favour interesting price offers not only at up-to-date components supply limited by the lead phase of production, but also at obsolete components needed for long life equipment maintenance and service (Livingstone, 2007). The unexpected ordered component supply cancelation for small companies can also open chance for counterfeits.

\section{COUNTERFEIT DETECTION METHODS}

The authenticity test methods can be basically branched as destructive and non destructive. Destructive methods require special equipment and tooling, for example a de-capsulation set for component package opening to find out whether the circuit system type and origin corresponds with the package labelling. Non-destructive methods encompass mainly costly analytical equipments like micro-focus X-ray units, ultrasound scanning microscopy and others (Schoppe \& Robertson, 2010). We need reference original component sample for comparative analysis for majority of these methods.

However, we can use also quite simple and cheaper methods for suspect components preliminary identification and assessment. The visual and simple optical analysis of component appearance, component labelling including producer logo, accompanying documentation check, package dimensional and shape analysis, pin condition analysis belong among such widely accessible methods (Thaler, 2007). The appearance analysis combined with an affordable component electric analysis constitutes an efficient tool applicable also outside the specialized laboratories. The knowledge of related technology and physical background can also help for internal structure possible changes identification.

Just V-I characteristics comparative analysis offers an interesting preventive method for relatively quick, simple and accessible new source component evaluation. Moreover, that method is still applicable for a standard diagnostics studies of technological and mistreatment consequences for a component with model V-I characteristics recorded in advance.

The method of electronic component V-I characteristic measurement and displaying has been using for circuit and component failure diagnostics since quite a long time ago (Polar Instruments, 1991). Its recent remarkable revival was caused both by counterfeit component occurrence increase and by the curve tracers sophisticated circuitry design noticing even small differences between the master and analysed component characteristics.

\section{COUNTERFEIT DETECTOR APPLICATION}

We are using the Sentry counterfeit IC detector by ABI Electronics Ltd. in our diagnostic laboratory. That device has 256 independent and identical measurement channels which can be arbitrarily contacted to all component pins providing their count is not higher than 256. In case of pin count higher than 256, the measurement performs successively in more than one step. Components with smaller pin count can be analysed in corresponding groups at the same time. There exists a wide range of package contact adapters for THT and SMD package components (ABI Electronics, 2011).

We can choose from more variants for component pin combination at the Sentry device. The Normal Mode combines all pins with the common pin like $\mathrm{V}_{\mathrm{ss}}$ or GND pin at integrated circuits. Transistors are free to choose any pin as the common 
pin. We talk about referring all pins to a chosen one. The Matrix Mode creates all possible pin combinations in successive couples. The preference for the Normal Mode or for the Matrix Mode depends on the particular component type and its production technology. The basic criterion for such choice is the higher sensitivity for V-I characteristic change. That sensitivity may differ at each Mode and for a particular component situation so that neither Normal Mode nor Matrix Mode has a general priority in advance. Following tables and figures illustrate results of our experiment with MOSFET power transistor samples analysis referred to the master transistor determined by the cooperating company.

\begin{tabular}{|l|c|}
\hline \multicolumn{2}{|c|}{ Scan Profile } \\
\hline Voltage Range: & $\pm 10 \mathrm{~V}$ \\
\hline Waveform: & Sine \\
\hline Source Resistance: & $100 \mathrm{kOhm}$ \\
\hline Frequency: & $100 \mathrm{~Hz}$ \\
\hline
\end{tabular}

Tab. 1. The particular scan parameters set for our experiment

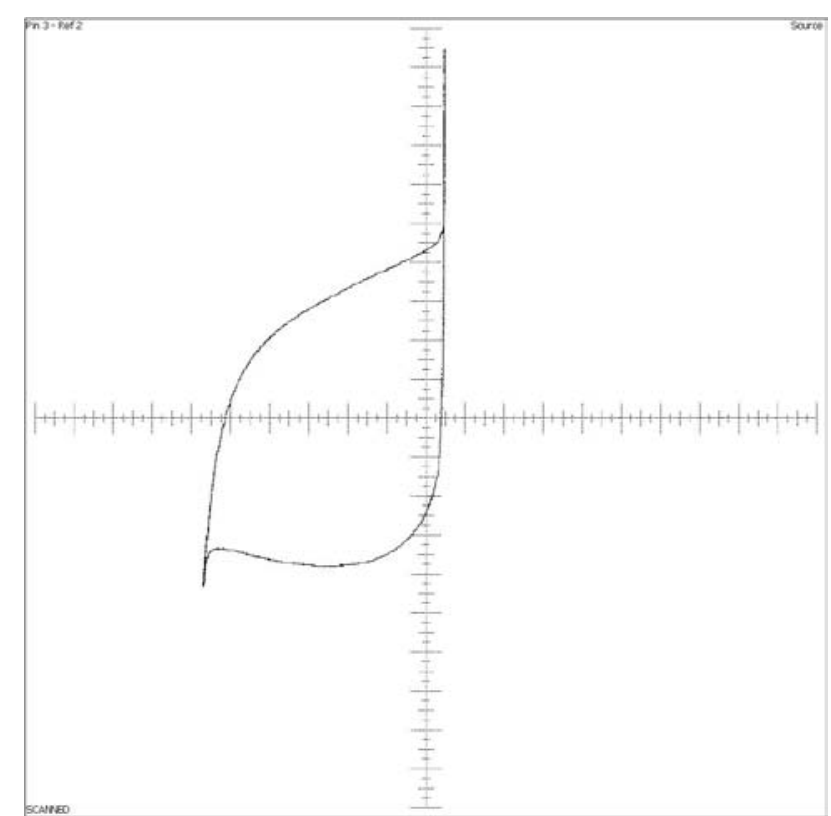

Fig. 1. MOSFET power transistor Source referred to Drain V-I characteristic example in Normal Mode

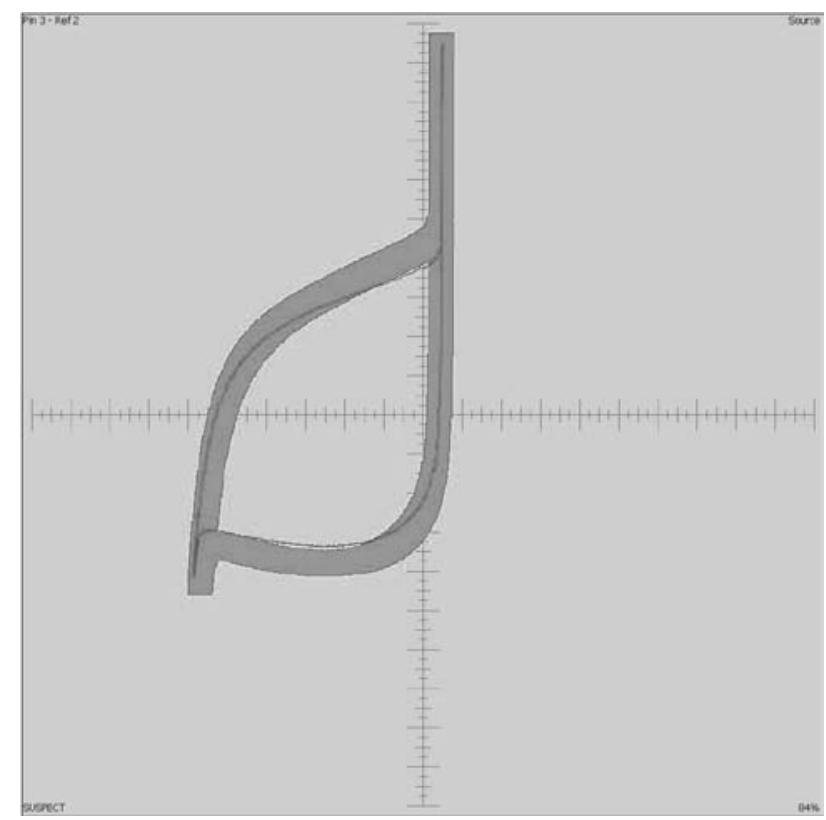

Fig. 2. MOSFET power transistor Source pin referred to Drain pin result in Normal Mode (84\%)

\begin{tabular}{|c|c|c|c|c|}
\hline \multicolumn{5}{|c|}{ 20N60C3 } \\
\hline \multirow[t]{2}{*}{ Sample } & \multicolumn{3}{|c|}{$\begin{array}{l}\text { NORMAL MODE } \\
\text { Ref - } 2 \text { (Drain) }\end{array}$} & \multirow[t]{2}{*}{ Result } \\
\hline & Pin1 & Pin2 & Pin3 & \\
\hline$M$ & 100 & 100 & 100 & Ref \\
\hline 1 & 57 & 100 & 64 & fail \\
\hline 2 & 59 & 100 & 83 & fail \\
\hline 3 & 62 & 100 & 84 & fail \\
\hline
\end{tabular}

Tab. 2. Sample group in Normal Mode with Reference Pin 2 Comparison Results Overview - M stands for the master

\section{CONCLUSION}

The presented result for the MOSFET power transistor illustrates the V-I characteristic comparative analysis possibilities for detecting and monitoring differences caused by diverse reasons and influences. Such differences can be caused by natural technological process dispersion at the same producer, by parameters variations among different producers, by differences caused by latent or apparent damages, and frequently also differences caused by a certain sort of the counterfeiting process.

Our further research aims at various components pin print study. We would like to extend the pin print database for particular component types and technologies as a guide for potential users. We are concentrated at component samples from industry area, and preferably at suspect components from new supply sources to document the real differences.

\section{ACKNOWLEDGMENTS}

The work has been supported by the Ministry of Education, Youth and Sports of the Czech Republic under the Research Plan No. MSM 7088352102 and by the European Regional Development Fund under the project CEBIA-Tech No. CZ.1.05/2.1.00/03. This support is very gratefully accepted.

\section{REFERENCES}

Crawford, M. et al., (2010). Defense Industrial Base Assesment: Counterfeit Electronics, Report of U.S. Department of Commerce, Bureau of Industry and Security, Office of Technology Evaluation, Available from: http://www.bis.doc.gov/defenseindustrialbaseprograms/osie s/defmarketresearchrpts/final_counterfeit_electronics_repor t.pdf Accessed: 2011-07-15

Hammond, R., (2010). Detection of Counterfeit Electronic Components, American Electronic Resource, Inc., Available from: http://www.aeri.com/detection-ofcounterfeit.asp Accessed: 2011-07-15

Livingston, H., (2007). Avoiding Counterfeit Electronic Components, In: IEEE Transactions on Components and Packaging Technologies, Vol. 30, No. 1, March 2007, pp. 187-189, 1521-3331

Schoppe, S. \& Robertson, G., (2010). Screening For Counterfeit Electronic Components, Process Sciences Inc., Available

from:

http://www.smtnet.com/library/files/upload/PSICounterfeits-Screening.pdf Accessed: 2011-07-15

Thaler, B., (2007). Identifying Counterfeit Components, National Electronics Manufacturing Center of Excellence, Available

from: http://www.empf.org/empfasis/2007/Nov07/tech_tipsr1107.html Accessed: 2011-07-15

ABI Electronics, (2011). Sentry Counterfeit Detector Manual and Application Notes, ABI Electronics Ltd., Barsley, United Kingdom, Available from: http://www.abielectronics.co.uk Accessed: 2011-07-15 